\title{
THE INDUSTRY AND EDUCATION NEXUS
} How one School Tackled Certification

\author{
Andrew Stein, Con Nikakis, John Bentley, Rob Jovanovic \\ School of Information Systems, Victoria University, Melbourne, Australia \\ Andrew.Stein@vu.edu.cu
}

Abstract: $\quad$ Over a period of 40 years, the Information Systems (IS) discipline has become an essential component in the employment of information technology personnel in business and government organisations. In recent times there have been discussions by IS professionals on how to best respond to developments in the information technology and communications industry. At the same time there has been a downturn in employment opportunities in this industry (ICT Skills Snapshot, 2004). Recent research also indicates that many of the entrylevel positions that graduates traditionally entered have diminished due to the economic downturn and to companies outsourcing positions to off-shore companies. This "in-progress" paper presents the path that one Australian University school took in introducing multiple certification programs in an endeavour to better connect a university school with ICT industry requirements. The certification programs include SAP, ITIL, I-Net + and Microsoft accredited programs. The results of this in-progress research show that flexibility in delivery mode and effective merging of curriculum and certification content is crucial to achieving successful programs.

Key words: Vendor certification, curriculum, certification implementation.

\section{INDUSTRY FOCUSSED TERTIARY EDUCATION}

"Mobile, flexible, highly-trained, industry-focussed, experienced ...", cries that are heard from the Information Technology industry in relation to the expertise that is expected from tertiary graduates these days. Until the recent cyclical downturn of the computer industry demand had been extremely high for graduates from tertiary institutions that could fit the chameleon-like nature of the computer industry's graduate skills deficit gap (NOIE, 2003; DES, 2001; Knight, 2001; DHFE, 2000). Much of this deficit 
was due to the rapidly changing nature and focus of the industry itself. It still is. The IT industry is constantly evolving with localised demand for graduates with skills in the latest technology upgrade (software and hardware). This demand exhibits much of the "here today, gone tomorrow" mentality that pervades industries that focus on new and developing but much hyped innovations. The modern marketing machine has trained many of us to "keep up with the technological Jones". Industry decision makers too, have been seduced by the hard sell. This trend is clearly manifested in the need to have employees and consequently IT graduates trained in the latest hardware and software. Industry is very quick to sound the alarm bells when there is a shortfall in the skills base (ICT Skills Snapshot, 2004).

\subsection{Government Demands on Tertiary Institutions}

The clamour for up-to-date, skill-focused, graduates has spilled over into the political arena. Governments through policy; and the press through emotive industry pieces; are demanding that tertiary institutions become focused on 'practical research', the delivery of 'skilled graduates' and be more 'outcome orientated'. This manifests itself in the requirement of governments to get greater value from the tertiary education dollar (SACES, 2002; ACNielson, 2000; Ahmadi \& Brabston, 1997; Castleman \& Coulthard, 1999). Universities, along with other tertiary institutions have in recent years gradually turned their focus to reacting to the pressures of governments and the community in general and at least have started talking about the need to increase their industry collaboration and in a number of instances have begun to action 'Collaborative Research' and 'Industry Partnerships'. A particular focus area is that of IT courses that run within Universities and TAFE institutions (SACES, 2002). A response within these courses has been to include industry-based training and industry liaison within and along side existing tertiary IT courses. It seems that IT courses and industry training are seen to be particularly conducive to using these approaches (Bartlett, 2002; Flynn, 2001; McCain, 2001; Filipczak, 2000).

\subsection{Certification: An avenue for Industry Collaboration?}

IT industry certification programs are seen as a respected and widelyestablished vehicle for attaining specific, practically based expertise - areas that many tertiary courses seem to lack or with which they have chosen not to be involved (Basu, 2002; McCain, 2001). Some tertiary institutions (mainly TAFE) have taken certification programs on board enthusiastically, to the extent that they are supplementing their own programs in a significant way (ITT, 2000). Others have ignored such programs labelling them as being 
too training or proprietary oriented to be considered as educative ("highbrow' response) (Flynn, 2001). In very recent times selection data (university selection popularity polls) have caught up with the significant downturn of employment experienced in the IT industry during 2001-2003. These trends place a greater burden on the University sector to react positively towards "adding value" to their offerings. For University IT/IS courses to be more industry relevant, practically focused and to add value in tune with industry and government funding pressure, IT/IS certification needs to be looked at more seriously than it has been to date (Mehaut, 2001).

\subsection{Certification Program Implementation}

The implementation of certification programs has been ad hoc and reactionary and little has been done to investigate the implementation of IT certification programs within tertiary IT/IS programs (Rothke, 2000; McCain, 2001). There are several distinct certification classifications:

- Industry body certification - ACS, PPP programs.

- Proprietary certification programs - MCSE, CNE, CISCO.

- Industry generalised certification programs - A+, i-Net+, Network+.

- Specific purpose certification - SAP professional, and

- Academic certification - Degree, certificate \& short course programs.

Assuming the case can be made to enhance existing programs with certification programs the 'Why' is answered, the 'How' can therefore be crucial to success. A wider classification is presented in Table 1.

Table 1. Certification models with example programs.

\begin{tabular}{|l|l|}
\hline Certification Model & Example Program \\
\hline Value-Added, End-On & ACS PPP program: Employment Driven, End-On \\
\hline Distance Learning & Charles Sturt University, Microsoft, CISCO, Sun \\
\hline Full Fee (Tertiary) & \\
\hline Full Fee (Private) & James Cook University, ITTI Master of IT \\
\hline Hybrid (Tertiary/Private), & $\begin{array}{l}\text { VU TAFE: Cisco Accreditation - Curriculum } \\
\text { Inclusive in Separate Subject }\end{array}$ \\
\hline Curriculum Inclusive & $\begin{array}{l}\text { PowerLan Microsoft Certification: Hybrid, } \\
\text { Curriculum Inclusive, Mapping }\end{array}$ \\
\hline Mapping to Industry Certification & SAP Professional Program \\
\hline Specific Subject & $\begin{array}{l}\text { Citrix Certification: Specific purpose, Employment } \\
\text { Driven, End-On }\end{array}$ \\
\hline $\begin{array}{l}\text { Industry Employment (Co- } \\
\text { Operative Education) }\end{array}$ & \\
\hline
\end{tabular}

This paper will focus on identifying forms of certification, their relevance to tertiary education, strengths and weaknesses and models of certification implementation. The endpoint of this research is recommendations for 
implementation of certification within the School of Information Systems, Victoria University. The formal research questions for this paper are:

- What types of certification programs would augment learning at VU?

- What models of certification implementation would be suitable for VU?

- Which model(s) is best suited to the needs of the School of IS?

\section{RESULTS AND DISCUSSION}

\subsection{ERP Certification at VU (Course Mapping)}

Victoria University has been a member of the SAP University Alliance since 1998. It adopted a faculty approach to introduction of ERP curriculum that was seen as a tool to reinforce many of the business and information systems concepts taught. The university now has approximately twenty-five subjects at both the undergraduate and postgraduate levels that incorporate SAP and related products. These subjects form part of master degree program that is taught in Australia, Singapore, China and Thailand in 2005. Even though the university has a well-established curriculum, it was also faced with the dilemma of how it could take advantage of industry acceptance of SAP. An important question that must be asked relates to the relevance of current ERP curriculum to industry requirements. The SAP University Alliance, established in the mid-nineties, closely followed the growth in ERP usage in industry. Universities which have worked very hard to develop ERP curriculum are now faced with the dilemma of evolving their curriculum to reflect the evolution of ERP systems and industry requirements. The curriculum employed by universities could be classified into one of four different curriculum approaches or a hybrid: Training into ERP, ERP via Business Processes, Information Systems Approach, ERP concepts, and The Hybrid.

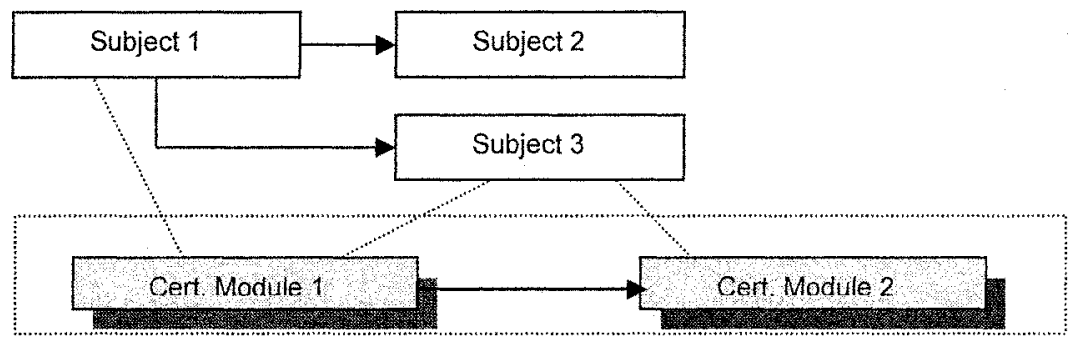

Figure 1. ERP Certification Implementation Model 
The VU approach uses elements of all models and could be classified as a hybrid. Certification of ERP education came about through the linking of subject content with SAP accredited programs. Students upon completion of subjects receive SAP industry accreditation that they can use to further their career prospects. The SAP certification model is displayed in figure 1.

\subsection{ITIL Certification at VU (Inclusive and End-On)}

ITIL is a widely recognized computer industry certification. It has about 100,000 certified professionals mainly in Europe, Australia and Canada. Information Technology Infrastructure Library (ITIL) is a set of best practices used to deliver high quality IT services derived from over a decade of work by thousands of IT workers world-wide. Because of its depth and breadth, the ITIL has become the de-facto world standard for IT best practices. ITIL frames all activity under Service Support and Service Delivery. By focusing on the critical business processes and disciplines needed to deliver services around IT, the ITIL provides a maturity path for IT that is not based on technology (ITIL, 2004).

The School of Information Systems has established an alliance with a private provider of ITIL training. The provider supplies an e-learning course at a $50 \%$ reduced cost to VU students. The international certification exam cost is unchanged (this cannot be reduced as it is an external independent body that controls ITIL certification). A student's participation is optional and will not affect their assessment in the subject. Advantages for students to undertake the certification include: gaining an industry accreditation in IT Service Management, being well placed for work-integrated learning positions, having exposure to ITIL practices used in over $60 \%$ of large Australian IT departments, helpful for other subjects (eg BCO2044 Computing Practice), and enhanced job prospects (the number of jobs being advertised in IT that require ITIL certification is growing rapidly. There are expanding job opportunities for ITIL practitioners).

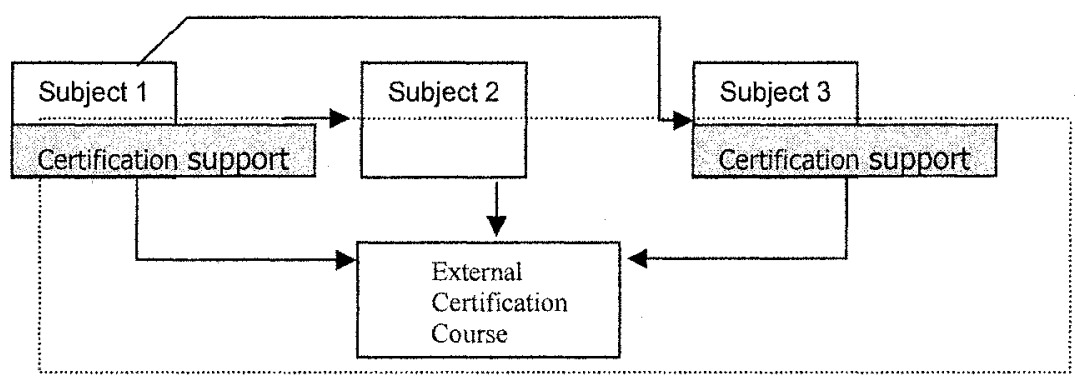

Figure 2. ITIL Certification Implementation Model 


\section{3 i-Net + Certification at VU (Curriculum Inclusive)}

Electronic Commerce Technologies is a subject (incorporating i-Net+ certification) that is an integral part of a group of four Electronic Commerce subjects that constitute the Electronic Commerce specialisation. CompTIA iNet + certification is an international industry-credentialing program developed for practitioners within the e-commerce technology field. This program has been developed by expert e-commerce industry practitioners, with objectives including Internet basics, Internet clients, EC development, networking, security and business concepts. The CompTIA i-Net+ certification program establishes base-line technical knowledge of Internet, intranet and e-commerce technologies, independent of specific Internetrelated career roles and proprietary implementations.

The $\mathrm{i}-\mathrm{Net}+$ certification program is undertaken during workshops so as to provide this "EC Consultant" capability. The i-Net+ workshop exercises provide the basis for putting together an EC Consultant Portfolio Document that is then used as the basis for the creation of an EC Consultant Credentialing document. The latter together with a presentation on a specific Electronic Commerce topic and a mid-semester i-Net+ Certification Test "license" the student to undertake the final stage of the major assignment - a multi-level solution of the provided case study.

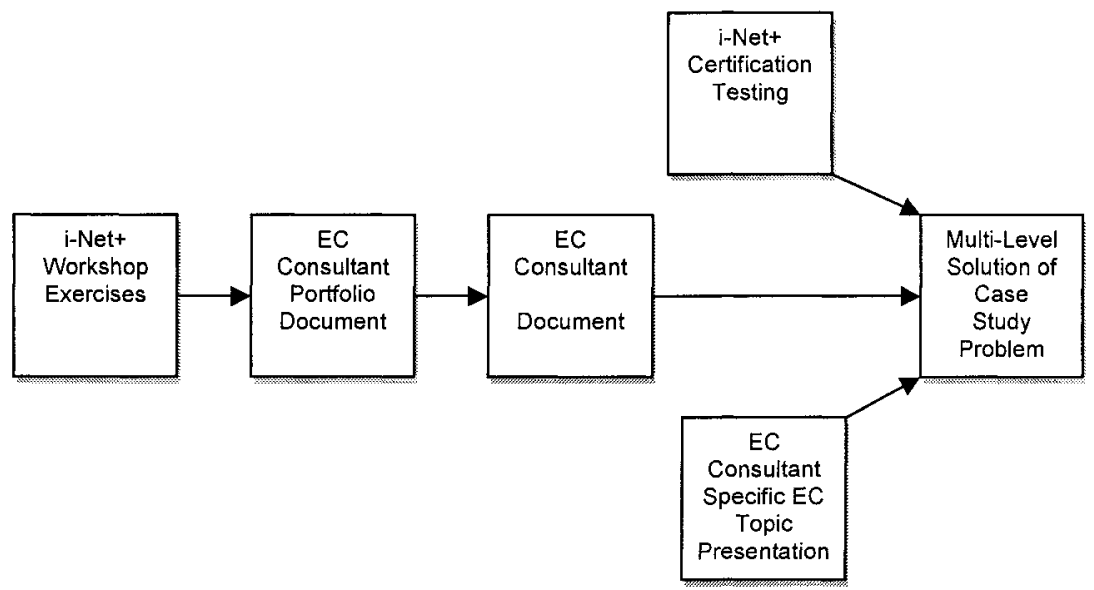

Figure 3. I-Net+ Certification Development

On completion of the course students are encouraged to sit the i-Net+ Certification Exam. To this end, the School of Information Systems has obtained educational CompTIA membership with the testing program being available to students at significantly lower rates. 


\section{CONCLUSION}

Certification literature points to benefits and pitfalls of certification that are described in Table 2. The benefits that underpin use of certification at Victoria University all relate to the transfer of skills from industry environs to educational programs. Undertaking SAP certification, ITIL, i-Net+ and Microsoft certification at VU attempt to better prepare students as they exit university programs and make the transition to the workforce.

Table 2. Benefits and pitfalls of certification programs.

\begin{tabular}{|l|l|}
\hline Strengths & Weaknesses \\
\hline Adding Value to degree programs & Exist to support training industry \\
Work related experience & Proprietary nature \\
Practical rather than just theoretical focus & Lack of educational rigor \\
"Up-to-Date" nature of certification programs & Often lacks "real-world" experience \\
Specific targeted content very relevant to & Industry partnership inadequate or unstable \\
employers & Too focused \\
Industry liaison opportunities & Training oriented rather than education \\
Adjunct to education programs offering & oriented \\
$\quad$ verifiable testing of skills and knowledge & "Value-for-Money" ignorance of \\
Potential employment advantages for graduates & certification \\
Precursor to licensing requirements & Too market and popularity driven \\
\hline
\end{tabular}

Additionally IT industry certification programs are seen as a respected and widely-established vehicle for attaining specific, practically based expertise - areas that many tertiary courses seem to lack or with which they have chosen not to be involved. In very recent times selection data (university selection popularity polls) have caught up with the significant downturn of employment experienced in the IT industry during 2001-2003. These trends place a greater burden on the University sector to react positively towards "adding value" to their offerings. The School of Information Systems has therefore seen it as a necessary strategy to investigate and has commissioned this current research into certification implementation models. This research has been focusing on identifying the various forms of certification, relevance to tertiary education, strengths and weaknesses of programs and models of certification implementation. The outcome of this research project is recommendations for adoption of certification within the School. Three varieties of implementation model (Course Mapping, Curriculum Inclusive, End-On) are being currently trialled within the School and the results will be reported in a later paper. 


\section{REFERENCES}

ACNeilson, (2000) Employer Satisfaction with Graduate Skills, Department of Education Training and Youth Affairs: Canberra, pp. 1-61.

Ahmadi, M. \& M. Brabston (1997) MIS Education: Differences in Academic Practice and Business Managers Expectations. Journal of Computer Information Systems, Winter, pp. $18-25$

Basu, K.S., (2002) Training strategies in the emerging hi-tech banking environment. Indian Journal of Training and Development, XXXI, (4), pp. 13-22.

Bartlett, K.R. (2002) The perceived influence of industry-sponsored credentials in the information technology industry. National Centers for Career and Technical Education (U.S.) (NCCTE), 10: pp. 83.

Castleman, T. \& D. Coulthard (1999) Not Just a Job: Preparing Graduates for Careers in the IS Workforce. [Tenth Australasian Conference on Information Systems], 1999, Wellington, NZ.

Dept for Education and Skills, (DES), (2001) An assessment of skill needs in information and communication technology / Dept for Education and Skills. Skills Dialogue: Listening to Employers. Vol. VII, Nottingham, U.K, Dept for Education and Skills, pp. 93.

Department of Higher and Further Education, (DHFE), (2000) A study of the Northern Ireland labour market for IT skills: a report prepared by the Priority Skills Unit, Northern Ireland Economic Research Centre., in A Northern Ireland Skills Task Force Report., Dept of Higher and Further Education, Training \& Employment: Belfast, pp. 68.

Filipczak, B., (2000) Certifiable!, Training, 32(8), pp. 38-40, 42.

Flynn, W.J., (2001) More than a matter of degree: credentialing, certification and community college, The Catalyst, 30(3), pp. 3-12.

ICT Skills Snapshot, (2004) The State of ICT Skills in Victoria, Department of Infrastructure, [http://www.itskillshub.com.au/render/exec/render_content.asp?subgroup=courses\&file=it +jobs+market+brighter\%2Ehtml\&title $=[\mathrm{T}+$ jobs + market+brighter]

ITIL, (2004) ITIL Survival, September 2004, [http://www.itilsurvival.com/]

ITT, (2000) Industry Report, Information-Technology Training: Teaching computer skills to American workers, Training, pp. 62-71.

Knight, K.S., (2001) Raising the bar on certification, The Catalyst, 30(3), p. 13-17.

McCain, M., (2001) Business Approach to Credentialing, Community College Journal, American Association of Community Colleges, 71(5), pp. 40-41.

Mehaut, P., (1999) Training, skills, learning: how can new models be developed? Vocational Training European Journal, 3, Thessaloniki, Greece, CEDEFOP, (18), pp. 3-7.

National Office Industry Education, (NOIE), (2003) Project Overview - ICT Skill Needs. [http://www.itskillshub.com.au/render/exec/render_content.asp?subgroup=courses\&file $=$ it +jobs+market+brighter\%2Ehtml\&title $=\mathrm{IT}+$ jobs+market+brighter $]$

Rothke, B.C. (2000) The Professional Certification Predicament. Computer Security Journal, 16 , pp. 29-35.

South Australian Centre for Economic Studies, (SACES), (2002) Unmet demand for information technology and telecommunications courses / report prepared by the SA Centre for Economic Studies for the Department of Education, Training and Youth Affairs, Canberra, pp. 128. 